\title{
Correction to: The Platonic-Freudian Model of Mind: Defining "Self” and "Other" as Psychoinformatic Primitives
}

\author{
Suraj Sood ${ }^{(\bowtie)}$
}

\begin{abstract}
Correction to:
Chapter "The Platonic-Freudian Model of Mind: Defining "Self" and "Other" as Psychoinformatic Primitives" in:

D. D. Schmorrow and C. M. Fidopiastis (Eds.): Augmented

Cognition, LNAI 12196,

https://doi.org/10.1007/978-3-030-50353-6_6
\end{abstract}

In the originally published version of chapter 6 , in section 4 , an incorrect statement was made. This statement has been corrected as follows: "...System 1 consists of unconscious affect and System 2 consists of conscious cognition...”. 